\title{
Sensitive intervention points in the post-carbon transition
}

Identify and exploit socio-economic tipping points and amplifiers.

J. D. Farmer ${ }^{1,2,5^{*}}$, C. Hepburn ${ }^{1,3}$, M. C. Ives ${ }^{1,3^{*}}$, T. Hale ${ }^{4}$, T. Wetzer ${ }^{1,6,7}$, P. Mealy ${ }^{1,3,8}$, R. Rafaty ${ }^{1}$, S. Srivastav ${ }^{1,3}$, R. Way $^{1,3}$

Conventional approaches to mitigating climate change are not working. Despite the actions pledged under the 2015 Paris Agreement, actual progress is falling well short (1). Given limited time and resources, traditional efforts, such as the climate stabilization wedge approach, are unlikely to be effective on their own (2). Physical science has shown how complex adaptive systems can cross critical thresholds ("tipping points") (3), such that a relatively small change can trigger a larger change that becomes irreversible (4), and where nonlinear feedback effects act as amplifiers (5). We propose to examine how to exploit similar sensitive intervention points (SIPs) and amplification mechanisms in socioeconomic, technological, and political systems to advance climate change mitigation. We focus on research and policies in which an intervention kicks or shifts the system so that the initial change is amplified by feedback effects that deliver outsized impact.

\section{SENSITIVE INTERVENTION POINTS}

There are two types of SIPs. The first involves a kick to the current state of the system, moving it onto a new trajectory without any change in the underlying system dynamics. If the new trajectory diverges rapidly from the old trajectory, then a small kick at the right point can trigger a large change. A small kick can be effective when the system is chaotic, or when it is near a critical point (Fig 1A). Subsidizing renewable energy sources to lower their costs provides an example of a kick.

The second type of SIP involves a shift in the underlying system dynamics, where the rules of the system itself change and trajectories alter dramatically. A shift can be effective even without a kick (Fig 1B). In the socio-economic-political sphere, a shift may entail a change in key concepts and

${ }^{1}$ Institute for New Economic Thinking at the Oxford Martin School, University of Oxford, Oxford, UK ${ }^{2}$ Mathematical Institute, University of Oxford, Oxford, UK. ${ }^{3}$ Smith School of Enterprise and the Environment, University of Oxford, Oxford, UK. ${ }^{4}$ Blavatnik School of Government, University of Oxford, Oxford, UK. ${ }^{5}$ Santa $\mathrm{Fe}$ Institute, Santa Fe, NM, USA. ${ }^{6}$ Faculty of Law, University of Oxford, Oxford, UK. ' $O x f o r d-M a n$ Institute of Quantitative Finance, University of Oxford, Oxford, UK. ${ }^{8}$ Bennett Institute for Public Policy, University of Cambridge, Cambridge, UK. Email: doyne.farmer@inet.ox.ac.uk,

matthew.ives@smithschool.ox.ac.uk institutions. For example, the shift from the rigid Kyoto regime to the more flexible (if still imperfect) Paris structure has altered the rules of the game, enabling new forms of cooperation (6). While the distinction between kicks and shifts is clear in theory, in practice SIPs typically involve a mixture of the two and can be difficult to distinguish.

By emphasizing the potential for purposeful intervention to drive nonlinear amplification in complex systems, our approach augments previous studies of social transitions $(7,8)$. However, we concentrate specifically on amplification effects (nonlinearities, positive feedbacks, or increasing returns) that can magnify the impact of an intervention. Knowing when this is possible requires an understanding of the underlying dynamics. Opportunities for SIPs may change over time as the system evolves, so paying attention to emerging windows of opportunity is essential (8).

SIPs can occur when nonlinearities cause trajectories to diverge rapidly. However, rates of divergence may vary dramatically, and some intervention points may be much more effective than others. Interventions can be particularly powerful if they drive the system into a new basin of attraction, making them difficult to reverse. SIPs also commonly arise in the presence of a critical threshold or tipping point, where a system sits at a boundary between qualitatively different types of behavior. In this circumstance, a small intervention can tip a system from one behavior to another.

Applying this conceptual framework, we examine four SIPs with the potential to contribute to rapid decarbonization.

\section{FINANCIAL DISCLOSURE}

Relatively modest changes to financial accounting rules or disclosure guidelines regarding climate change risks could have outsized effects. Many companies are currently failing to disclose and account for the risks to their balance sheets from the transition necessary to limit warming to 1.5 or $2^{\circ} \mathrm{C}$, as well as failing to account for the physical risks that climate change will bring. A recent study by a UK-based institutional investor of eight major oil and gas companies suggests that, due to optimistic assumptions about long-term oil prices, there may be a systemic overstatement of capital and performance. Will oil prices really rise at $2 \%$

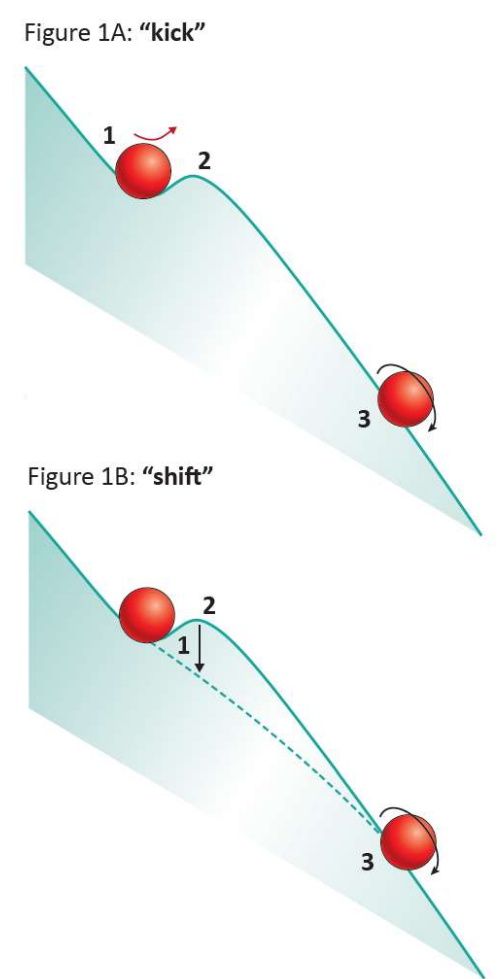

Fig. 1. A modest change can trigger an outsized response to a state variable of interest. This is achieved either (Figure 1A) by perturbing a state variable, called a kick, so that it moves to a new trajectory in the current system or (Figure 1B) by modifying the system so that its trajectory is altered, called a shift. In this example, following the intervention, the ball rolls on its own.

per annum from $\$ 70-\$ 80$ a barrel in 2020/21? These assumptions are likely inconsistent with the Paris Agreement, which would reduce demand for oil and, other things being equal, imply prices that are closer to a range of $\$ 20-40$ a barrel. Changing price assumptions matter - in 2017, the company Total reported that a reduction in assumed prices from $\$ 80$ to $\$ 72$ a barrel would lead to asset impairments of over $\$ 4 b n$, cutting profits in half (9). What would the impact be at $\$ 20-\$ 40$ a barrel?

There is a committed minority of investors who are aware of climate risks and are pushing for more openness. A change in accounting standards or disclosure guidelines could cause a substantial repricing of fossil assets (e.g. fossil fuel reserves 
and securities valuations), reducing the ability of the oil and gas sector to develop new fields, hence reducing committed emissions. Preventing such investments lowers the economic, social, and political costs of transforming the energy industry, as it levels the playing field for renewables, reduces the likely quantum of stranded assets, and increases the credibility of climate targets. Regulators in many countries, including Australia, the Netherlands, and the United Kingdom, are demonstrating increasing awareness of the potential impact of accounting guidance.

\section{CHOOSING TECHNOLOGY INVESTMENTS}

A kick to clean energy technologies could trigger feedbacks that make the energy transition cheaper and faster. If costs fall predictably with deployment, as they have in the past, investment in specific clean technologies would push them past the tipping point where they become economically competitive with brown incumbents, even without a carbon price. While the transition to renewables has so far only made a small reduction in emissions, it has the potential to accelerate decarbonization dramatically, providing another good example of a SIP.

Which technologies should we invest in? In standard portfolio theory, investments do not affect outcomes, and diversification is strongly favored. In contrast, technology investments strongly influence outcomes, making the portfolio allocation problem highly nonlinear and causing outcomes to be sensitive to investments (10). Too much diversification means that nothing makes much progress - rapid progress requires concentrating resources.

History suggests that in the long-run some technologies are much more responsive to investment than others. For energy technologies, the real costs of oil, coal, and natural gas have not changed much in over a century. Nuclear power costs about the same, or more, than it did sixty years ago. In contrast, renewable energy sources such as solar photovoltaics (PV) and wind have experienced rapid, persistent cost declines. The real cost of solar PV modules has dropped by more than a factor of 6,000 since inception in 1956 (11). Since 1990 costs have dropped at $10 \%$ per year while deployment has increased at $26 \%$ per year. Despite far greater investment and subsidies, fossil fuel costs have stayed within an order of magnitude for a century. Unless technological change is somehow "purely exogenous", this suggests that the cost of solar PV is, in the long-run, more responsive to investment than fossil fuels or nuclear power.

When there is a cheap incumbent like fossil fuels, and an initially expensive challenger like solar PV, a marginal investor solely focused on cost will always choose the incumbent. This creates a danger that the incumbent becomes stuck. A far-sighted public investor, in contrast, can invest in the most responsive technologies to make them cheaper. The optimal strategy is to invest heavily in the challenger early on (10).

Solar PV and wind have now been supported (or 'kicked') to the extent that they are at, or near, the tipping point where they are competitive with the cheapest alternatives. If their deployment continues to increase at its present rate, by 2030 the prevailing cost of electricity will very likely become cheaper than it has been during the last century (11). This could pay handsome returns and dramatically lower the cost of the green energy transition. To realize these gains, we must make intelligent choices about developing the energy storage technologies that are essential to deal with the intermittency of renewables.

A SIP strategy would seek to better understand the causal mechanisms of technological improvement, and then favor technologies where evidence supports the likelihood of rapid, investment-driven cost declines to outcompete incumbents. By raising the very real possibility that intelligent investments in the green energy transition could be financially profitable, as well as environmentally beneficial, this SIP could accelerate progress by neutralizing resistance to change based on perceived economic costs.

\section{POLITICAL MOBILIZATION}

A regime shift towards green technologies will also require public support and adoption (6). However, despite widespread belief across countries that climate change exists, and needs addressing, citizens have rarely prioritized the issue. This means that proclimate policies have struggled to garner sufficient political salience to overcome powerful incumbent interest groups. Nevertheless, the existence of a "silent" proclimate majority creates the possibility of a SIP, provided political entrepreneurs can activate it.

Social scientists have long studied the power of small groups of influencers in, for example, political revolutions. A few "radicals" can spark a revolution simply by demonstrating to the majority that their beliefs are more commonly held than they had thought (12). The power of influencers has also been demonstrated in laboratory settings, where a committed minority with unwavering opinions can have an outsized effect on others whose opinions are less firm. Theoretical models show that the committed minority fails to grow if it is less than a critical threshold of the total population, but above the threshold grows rapidly and becomes prevalent (13).

Such findings could have important implications for climate policy: If a latent majority supports ambitious climate action, and if the size of the committed minority is close to a critical threshold, then a small kick to raise the issue's political salience may have an outsized effect. Indeed, we observe an increasing number of political entrepreneurs attempting exactly this strategy. Student activists like Greta Thunberg who are driving a wave of school strikes around the world, are finding new discourses to change the political salience of the issue. Striking exhibits increasing returns: the costs of striking fall, and the benefits rise, as more students coordinate on the same behavior, as does the potential for political change. Similarly, proponents of the Green New Deal in the United States are attempting to harness the quiet pro-climate majority to generate a broader coalition formed around a wider social agenda. Will these movements have any impact? There are several key questions. Does the net benefit of political action rise as others take action? Is the current distribution of political beliefs close to a critical point? Does the intervention kick the system into a different basin of attraction?

\section{UK CLIMATE CHANGE ACT}

The United Kingdom's political climate of 2007-8 provided a window of opportunity that led to the Climate Change Act of 2008 (14), and provides a good example of a SIP (in this case a shift). Drafted by a small number of policy entrepreneurs from NGOs, academia, and parliament in the wake of the government-sponsored Stern Review on the economics of climate change, the Act passed with a near-unanimous vote, during a rare multi-party consensus prior to the 2009 UN climate meeting in Copenhagen. The Act established the world's first national legislation mandating greenhouse gas reductions by 2050 of 80 percent relative to 1990 levels, unconditional on other countries' actions.

While the Act itself did not immediately kick the system into a new state, it shifted the 
institutional conditions under which future governments decide on climate policy. It creates new institutional bodies, including the expert-led Committee on Climate Change, tasked with formulating carbon budgets every five years and reporting regularly to parliament and the cabinet. Government policies that fall short are publicly exposed, giving rise to legal challenges. By creating a long-term goal, an independent review body, and a regular ratcheting cycle, the Act makes it more difficult for future governments to backslide, and creates additional pressure for ambitious steps in the future (14), creating self-fulfilling beliefs in the post-carbon transition. Over the decade since 2008, $\mathrm{CO}_{2}$ emissions in the UK have fallen dramatically.

The UK Climate Change Act inspired the Paris Agreement's inclusion of a long-term target and ratchet mechanism, and its institutional features have been adopted by other jurisdictions, further amplifying its impact. Countries like New Zealand, Chile, and Sweden are looking at similar approaches (14).

\section{RESEARCH AND DEPLOYMENT}

These examples illustrate how many areas of policy and practice could be transformed by taking the SIP perspective. But substantial work lies ahead. A first step is to proactively and systematically identify potential SIPs, informed by complex systems theory. Are there regions of the socioeconomic system with critical thresholds, 'windows of opportunity' or tipping points? If not, what shift might create such dynamics? How close is the system to a sensitive region? Is there an intervention to kick the system in the right direction? What are the possible amplification mechanisms, following the kick or a shift? These might include network externalities, self-fulfilling beliefs, norm cascades, learning curves, bandwagon effects, and other phenomena with positive feedback effects.

In some cases, this simply means thinking about familiar issues in a different way. There are connections here with the literature on socio-technical transitions, particularly in the strategic management of niche technologies (7). In other cases, a climate strategy informed by SIPs would place an even stronger emphasis on exploiting positive feedbacks, nonlinearities and the potential for chaotic behavior in complex systems. Each of the four examples discussed above came into being without an explicit complex systems perspective, but a holistic view could help systemically identify such interventions, and to target them most effectively.

The second step involves empirically characterizing the system dynamics, so that the intervention can be best designed. An excellent example is a study that tested and implemented approaches to prevent bullying in schools by identifying and recruiting key 'social referent' students to alter social norms (15). Such a methodology might be applied to identifying tipping points in attitudes and actions towards climate change mitigation. Modelling the key actors in the system is necessary to specify the intervention: who should do what, when?

Current integrated assessment models, used to evaluate the economics of climate mitigation, provide an example of why the SIPs approach is necessary. Most such general equilibrium models omit key nonlinear feedback effects that are essential for understanding SIPs and their impact. New analytical frameworks that incorporate methods from dynamical systems, network analysis and agent-based modeling at a granular level can help capture essential nonlinear feedback mechanisms. Such models could provide richer and more accurate insights into costs and benefits of interventions with amplified effects. More realistic models may increase trust and interest in their results, and lead to better informed policy. This might itself constitute an intervention in a sensitive area of the socio-political system.

Creating a world of zero greenhouse gas emissions is a revolutionary enterprise that will require dramatic changes to our physical infrastructure, economy and society, and their interactions with each other. There is strong coupling between these different domains, which makes models built within silos unable to provide the guidance needed. This is already apparent from the four examples given above: Support for new green technologies depends on political mobilization, and can be amplified by improved financial disclosures. All of these benefit from a regulatory framework that encourages decarbonization beyond political cycles.

We also need a multi-disciplinary framework integrating perspectives from the social, physical and natural sciences, as well as the humanities. National and regional funding calls must seek to promote true interdisciplinary teams that span socioeconomic, political, environmental, and sociotechnical approaches, and are capable of generating conceptual or empirical breakthroughs that might not be reached in isolation. Fine grained complex systems models of the economy and technological change should be coupled with models of opinion dynamics and the financial and legal systems. The change that we are about to make and the consequences of failure are so great that we cannot afford to fly blindly into the future.

\section{References and Notes:}

1. A. Pfeiffer, C. Hepburn, A. Vogt-Schilb, B. Caldecott, Environ. Res. Lett. 13, 054019

(2018).

2. S. Pacala, R. Socolow, Science $305,968-72$

(2004).

3. T. M. Lenton et al., Proc. Natl. Acad. Sci.

105, 1786-1793 (2008)

4. D. H. Meadows, Sustain. Inst., 1-19 (1999).

5. M. S. Torn, J. Harte, Geophys. Res. Lett. 33

(2006), doi:10.1029/2005GL025540.

6. T. Hale, "Catalytic cooperation" (BSG-WP2018/026, Oxford, UK, 2018).

7. B. K. Sovacool, D. J. Hess, Soc. Stud. Sci. 47, 703-750 (2017).

8. F. W. Geels, B. K. Sovacool, T. Schwanen, S.

Sorrell, Science in press, doi:10.1126/science.aao3760

9. N. Landell-Mills, "Are oil and gas companies overstating their position?" (2018), (available at https://www.sarasinandpartners.com/docs/ default-source/esg/are-oil-and-gascompanies-overstating-their-position) 10. R. Way, F. Lafond, F. Lillo, V. Panchenko, J. D. Farmer, J. Econ. Dyn. Control (2019), doi:10.1016/J.JEDC.2018.10.006.36.

11. F. Lafond et al., How well do experience curves predict technological progress? A method for making distributional forecasts. Technol. Forecast. Soc. Change. 128, 104-117 (2018)

12. T. Kuran, Public Choice 61, 41-74 (1989).

13. D. Centola, J. Becker, D. Brackbill, A. Baronchelli, Science 360, 1116-1119 (2018). 14. M. Nachmany, S. Fankhauser, J. Setzer, A. Averchenkova, Global trends in climate change legislation and litigation: 2017 update (2017) (available at http://eprints.lse.ac.uk/80447/). 15. E. L. Paluck, H. Shepherd, P. M. Aronow, Proc. Natl. Acad. Sci., 2016, doi:10.1073/pnas.1514483113. 